\section{Prolegómenos}

Derecho y Valores
Prolegómenos. Derechos y Valores

ISSN: 0121-182X

derechos.valores@umng.edu.co

Universidad Militar Nueva Granada

Colombia

Cortázar, María Graciela

LAS GARANTÍAS JUDICIALES. ANÁLISIS A PARTIR DE LOS ESTÁNDARES DE LA JURISPRUDENCIA DE LA CORTE INTERAMERICANA DE DERECHOS HUMANOS

Prolegómenos. Derechos y Valores, vol. XV, núm. 30, julio-diciembre, 2012, pp. 65-79 Universidad Militar Nueva Granada

Bogotá, Colombia

Disponible en: http://www.redalyc.org/articulo.oa?id=87625443004

Cómo citar el artículo

- Número completo

- Más información del artículo

Página de la revista en redalyc.org

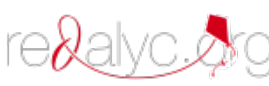

Sistema de Información Científica

Red de Revistas Científicas de América Latina, el Caribe, España y Portugal Proyecto académico sin fines de lucro, desarrollado bajo la iniciativa de acceso abierto 


\title{
LAS GARANTÍAS JUDICIALES. ANÁLISIS A PARTIR DE LOS ESTÁNDARES DE LA JURISPRUDENCIA DE LA CORTE INTERAMERICANA DE DERECHOS HUMANOS*
}

\author{
María Graciela Cortázar**
}

Fecha de Recibido: 17 de octubre de 2012

Fecha de Aprobado: 26 de noviembre de 2012

Articulo de Reflexión

Forma de citación: Cortázar, M. G. (2012). Las Garantías Judiciales. Análisis a partir de los estándares de la jurisprudencia de la Corte Interamericana de Derechos Humanos. Revista Prolegómenos. Derechos y Valores, 15, 30, 65-79.

\begin{abstract}
Resumen
Se analizanlas garantías convencionales previstas en los artículos 8 y 25 de la Convención Americana sobre Derechos Humanos a la luz de la jurisprudencia de la Corte Interamericana. El derecho a ser oído, a la presunción de inocencia, al juzgamiento en plazo razonable, a la acusación clara y determinada, al juez natural, constituyen connotaciones de las garantías convencionales previstas, especialmente, en la Convención que, además, se proyectan en un sinnúmero de aplicaciones concretas que la Corte ha señalado a través de los distintos casos juzgadospor ella y que le aportan un sentido específico. Se concluye que la Corte Interamericana de Derechos Humanos ha desarrollado un proceso de estandarización referente al plazo razonable de los procesos seguidos dentro de la jurisdicción interna de los países miembros, evitando la incertidumbre e inseguridad jurídica para las partes, así como se procurala uniformidad en el manejo de los tiempos procesales dentro de los ordenamientos jurídicos internos.
\end{abstract}

\section{Palabras clave:}

Garantías judiciales, derecho a ser oído, presunción de inocencia, juez natural, plazo razonable.

* Artículo de reflexión que pertenece al Proyecto de Investigación: "Influencia del Sistema Interamericano de Protección de Derechos Humanos en el Sistema Penal Argentino". La investigación, sistematización y redacción d el presente artículo ha contado con la colaboración esencial de las abogadas Laura Krotter, Lucía Alonso Angelossi y Paula Riganti, y la estudiante Jessica Neilor.

** Abogada, Magister y Especialista en Derecho Penal. Profesora del Departamento de Derecho de la Universidad Nacional del Sur. Correo electrónico: cortazargraciela@gmail.com 


\title{
JUDICIAL GUARANTEES. \\ ANALYSIS BASED ON THE STANDARDS \\ OF THE INTER-AMERICAN COURT OF HUMAN RIGHTS
}

\begin{abstract}
This article will analyze the guarantees provided in the articles 8 and 25 of the American Convention on Human Rights in the light of the jurisprudence of the Inter-American Court. The right to be heard, the presumption of innocence, the reasonable time judgment, a clear and specific accusation, a natural judge, are connotations of the conventional guarantees provided in the Convention that are projected in endless concrete applications that the Court has issued through all the cases that she has judged and that grant them a specific sense. It is concluded that the Inter-American Court of Human Rights has developed a standardization process regarding the reasonable time of processes followed in the internal jurisdiction of member countries, avoiding juridical incertitude and insecurity for the parties and establishing uniformity in the management of process times of the internal legal codes.
\end{abstract}

\section{Keywords}

Judicial guarantees, right to be heard, presumption of innocence, natural judge, reasonable time.

\section{JULGAMENTO JUSTO. ANÁLISE COM BASE NOS PADRÕES DA JURISPRUDÊNCIA DA CORTE INTERAMERICANA DE DIREITOS HUMANOS}

\begin{abstract}
Resumo
Analisamos as garantias convencionais nos termos dos artigos 8 e 25 da Convenção Americana sobre Direitos Humanos, à luz da jurisprudência do Tribunal. O direito de ser ouvido, de ser presumido inocente, a julgamento dentro de um prazo razoável a alegação clara e específica, o juiz, são conotações convencionais de garantias previstas na Convenção especialmente projetadas também em inúmeras aplicações práticas que o Tribunal indicou através dos vários casos decididos por ele e dar-lhe um significado específico. Conclui-se que o Tribunal de Direitos Humanos desenvolveu um processo de padronização em relação ao tempo razoável do processo da jurisdição interna dos países membros, evitando a incerteza e insegurança jurídica para as partes e busca a uniformidade na processo de gestão do tempo dentro dos sistemas jurídicos internos.
\end{abstract}

\section{Palavras-chaves}

Garantias judiciais, direito de ser ouvido, presunção de inocência, juiz natural, tempo razoável. 


\section{INTRODUCCIÓN}

La Corte ha tenido oportunidad de abordar la cuestión de las garantías judiciales a través de innumerables fallos y por distintos hechos en los que aparecía cuestionada su aplicación como derecho esencial.

Esta determinación de contenido de las garantías judiciales, el alcance que debe dárseles y los distintos ámbitos de aplicación constituyen un problema de investigación que se pretende abordar y resolver en el presente trabajo.

¿Cuál es el alcance del derecho a ser oído?¿En qué procesos debe entenderse de aplicación el derecho de defensa? ¿Es solamente referido al proceso penal o constituyen las garantías judiciales un conjunto de garantías que abarcan otros procedimientos en los que se discuta la vigencia de un derecho personal?

La Corte Interamericana, como órgano jurisdiccional del Sistema Interamericano de Derechos Humanos, interpreta la Convención y le otorga sentido de aplicación a sus normas en el caso concreto, pero además conformando doctrina jurisprudencial obligatoria dentro de los Estados. Esta consecuencia de alta importancia también se erige en un problema de investigación que pretende analizarse y dar conclusiones, para ser un aporte al estado actual de los estudios sobre el Sistema Interamericano de Protección de Derechos Humanos.

\section{LAS GARANTÍAS JUDICIALES EN EL PACTO DE SAN JOSÉ DE COSTA RICA}

La Convención Americana sobre Derechos Humanos consagra en los artículos 8 y 25 los derechos que poseen las personas y que deben garantizar los Estados en relación al servicio de justicia y los procesos judiciales. De cada una de estas garantías judiciales, se desprenden obligaciones para el Estado que ha ratificado la Convención. Así, conforme a estos derechos y al artículo 1.1, existe para todo Estado el deber de respetar y garantizarlas, sin discriminación alguna, a toda persona que esté bajo su jurisdicción. El artículo 2 convencional, también consagra una garantía general que en distintas ocasiones la Corte ha encontrado violada en relación con las garantías judiciales. En este sentido, el Estado tiene el deber de adoptar medidas legislativas o de otra índole que permitan hacer efectivos los mencionados derechos.

\section{A. Concepto y contenido de las garantías judiciales previstas en los artículos 8 y 25 del Pacto de San José de Costa Rica}

Tal como lo ha definido la Corte Interamericana de Derechos Humanos, las garantías judiciales son los medios de defensa que sirven para proteger, asegurar o hacer valer la titularidad o el ejercicio de un derecho. En este sentido, la propia Corte afirma que: "los Estados Partes tienen la obligación de reconocer y respetar los derechos y libertades de la persona, también tienen la (¿??) de proteger y asegurar su ejercicio a través de las respectivas garantías (art. 1.1), vale decir, de los medios idóneos para que los derechos y libertades sean efectivos en toda circunstancia".

He aquí una conceptualización objetiva de lo que debe entenderse por garantías judiciales; esto es: aquellos medios con idoneidad para hacer valer los derechos de las personas. Respecto a la naturaleza judicial de las garantías, la Corte ha establecido que éstas "deben ser no sólo indispensables sino judiciales. Esta expresión no puede referirse sino a medios judiciales idóneos para la protección de tales derechos, lo cual implica la intervención de un órgano judicial independiente e imparcial, apto para determinar la legalidad de las actuaciones que se cumplan dentro del estado de excepción".

La Corte estima que: “(...) la determinación de qué garantías judiciales son indispensables para la protección de los derechos que no pueden ser suspendidos será distinta según los derechos afectados. Las garantías judiciales "indispensables" para asegurar los derechos relativos a la integridad de la persona necesariamente difieren de aquellas que lo protegen. "El Pacto de San 
José de Costa Rica enuncia en los artículos8 y 25 aquellos derechos que aparecen integralmente enunciados a partir de la jurisprudencia de la Corte y dela elaboración conceptual del Sistema como "garantías judiciales", en el sentido visto previamente y que la propia Corte ha definido.

Así, se tiene por cierto que el derecho a ser oído, a un juez imparcial, a la defensa, a un recurso eficaz, entre otros, constituyen el conjunto de garantías judiciales que son ese material imprescindible para hacer valer los derechos reconocidos en la Convención. Ahora bien, la jurisprudencia revela la necesidad de "bajar a concreto", de especificary definir en situaciones específicas el contenido, el alcance, el sentido que debe darse alas garantías judiciales previstas en los artículos 8 y 25 , lo que aún se encuentra en plena evolución conceptual.

La siguiente sistematización contiene todo aquello que la Corte Interamericana ha dicho en relación contodos los aspectos que involucran los artículos 8 y 25 de la Convención Americana sobre Derechos Humanos. Es intención mostrar en una dimensión concretalos alcances que deben darse hasta el presente, en palabras de la Corte Interamericana, alas garantías judiciales.

\section{B. Sistematización de la Jurisprudencia: ¿Qué ha dicho la Corte Interamericana en relación con los artículos 8 y 25 de la CADH?}

A continuación se revisará el desarrollo jurisprudencial realizado en relación con los derechos contenidos en las normas que constituyen el objeto de la presente investigación.

\section{DERECHO A SER OIDO}

Según la Corte Interamericana, de este apartado se desprende que las víctimas de las violaciones de los derechos humanos o sus familiares deben contar con amplias posibilidades de ser oídos y actuar en los respectivos procesos, tanto en procura del esclarecimiento de los hechos y del castigo de los responsables como en busca de una debida reparación(Corte IDH, 19 de noviembre de 1999, párr. 227; 16 de agosto de 2000, párr. 129; 31 de enero de 2001, párr. 81; 6 de diciembre de 2001, párr. 59 y 5 de julio de 2004, párr. 186). Y ha entendido el máximo Tribunal Regional que el ejercicio de tal derecho debe llevarse a cabo ante un juez o tribunal imparcial, siendo así que "...toda persona sujeta a un juicio de cualquier naturaleza ante un órgano del Estado deberá contar con la garantía de que dicho órgano sea imparcial y actúe en los términos del procedimiento legalmente previsto para el conocimiento y la resolución del caso que se le somete (Corte IDH. 2 de julio de 2004, párr. 169)”.

Así, no sólo se ha reiterado el concepto elemental que define a esta garantía a lo largo de su jurisprudencia (Corte IDH. 01 de marzo de 2005, párr. 64) sino que asimismo se la ha vinculado con el derecho de los familiares de las presuntas víctimas y la obligación estatal de que "... lo sucedido a estas últimas sea efectivamente investigado por las autoridades del Estado; se siga un proceso contra los presuntos responsables de estos ilícitos; en su caso, se les impongan las sanciones pertinentes, y se reparen los daños y perjuicios que dichos familiares han sufrido" (Corte IDH. 01 de marzo de 2005, párr. 64).

Esta garantía se profundizó al entenderse en el Caso Apitz Barbera y otros ("Corte Primera de lo Contencioso Administrativo") vs. Venezuela (Corte IDH. 5 de agosto de 2008, párr. 75) que “... del artículo 8.1 de la Convención no se desprende que el derecho a ser oído debe necesariamente ejercerse de manera oral en todo procedimiento. Lo anterior, no obstaría para que la Corte considere que la oralidad es una de las "debidas garantías" que el Estado debe ofrecer a los justiciables en cierto tipo de procesos.

La Corte ha continuado sosteniendo lo relevante de proporcionar a las víctimas y sus familiares la posibilidad de ser oídos en los recientes fallos Fernández Ortega y otros vs. México (Corte IDH. 30 de agosto de 2010, párr.192) y Rosendo Cantú y otra us. México (Corte IDH. 31 de agosto de 2010, párr. 176), siendo esclarecedora la reflexión formulada por el Juez CancadoTrindade en su voto razonado (Corte IDH. 2 de agosto de 2008, 
párr. 60) en el fallo del Penal Miguel Castro Castrous. Perú, donde ha referido que según el "...imperativo kantiano, según el cual ninguna persona debe ser tratada como un simple medio (ni siquiera para la "operación de la justicia"), sino más bien como un fin en sí misma.

Esto requiere escucharla atentamente en audiencia pública, darle las razones que fundamentan la decisión judicial que la concierne, aclarar las dudas que pueda todavía tener después de dicha decisión. Sólo así la persona justiciable no se sentirá como un medio (para la labor de otros), y pasará a sentirse como un fin en sí misma”.

Esta garantía debe interpretarse, a la luz de la propia jurisprudencia regional, de manera amplia de modo que dicha interpretación se apoye tanto en el texto literal de esa norma como en su espíritu, y debe ser apreciado de acuerdo con el artículo 29, inciso c) de la Convención, según el cual ninguna disposición de la misma puede interpretarse con exclusión de otros derechos y garantías inherentes al ser humano o que se deriven de la forma democrática representativa de gobierno (Corte IDH. 24 de enero de 1998, párr. 96). En la misma oportunidad, como así también en el fallo Durand y Ugarte Vs. Perú (Corte IDH. 16 de agosto de 2000, párr. 128), la Corte entendió que el artículo comprende también el derecho de los familiares de la víctima a las garantías judiciales, por cuanto "todo acto de desaparición forzada sustrae a la víctima de la protección de la ley y le causa graves sufrimientos, lo mismo que a su familia"; ello conforme la Declaración de Naciones Unidas sobre la Protección de Todas las Personas contra las Desapariciones Forzadas, artículo 1.2.

\section{DERECHO A LA PRESUNCION DE INOCENCIA}

Desde que la Corte se ha pronunciado respecto a este derecho ha entendido que el mismo, "tal y como se desprende del artículo 8.2 de la Convención, exige que una persona no pueda ser condenada mientras no exista prueba plena de su responsabilidad penal. Si obra contra ella prueba incompleta o insuficiente, no es procedente condenarla, sino absolverla (Corte IDH.18 de agosto de 2000. Serie C No. 69, párr. 120)".

Y es por ello que este principio constituye un fundamento de las garantías judiciales (Corte IDH. 24 de junio de 2005, párr. 111; 25 de noviembre de 2005, párr. 160 y22 de noviembre de 2005, párr. 198),ya que de lo que en aquel apartado se dispone deriva la obligación estatal de no restringir la libertad del detenido más allá de los límites estrictamente necesarios para asegurar que aquél no impedirá el desarrollo eficiente de las investigaciones ni eludirá la acción de la justicia. En este sentido, la prisión preventiva es una medida cautelar, no punitiva (Corte IDH.7 de septiembre de 2004, párr. 180; 24 de junio de 2005, párr. 111; 22 de noviembre de 2005, párr. 198; 25 de noviembre de 2005, párr. 106 y 21 de noviembre de 2007, párr. 145).

Así, entendió la Corte Regional en el fallo Ricardo Canese vs. Paraguay (Corte IDH. 31 de agosto de 2004, párr. 154) que el derecho a la presunción de inocencia es un elemento esencial para la realización efectiva del derecho a la defensa, y acompaña al acusado durante toda la tramitación del proceso hasta que una sentencia condenatoria que determine su culpabilidad quede firme. Así, la falta de prueba plena de la responsabilidad penal en una sentencia condenatoria constituye una violación al principio estudiado (Corte IDH. 18 de agosto de 2000, párr. 121 y 26 de noviembre de 2010, párr. 183). Este derecho implica que el acusado no debe demostrar que no ha cometido el delito que se le atribuye, ya que el onus probandi corresponde a quien acusa (Corte IDH. 26 de noviembre de 2010, párr. 182).

Y de dicho principio esencial se desprende la correlativa exigencia al Estado de no condenar informalmente a una persona o emitir juicio ante la sociedad, contribuyendo así a formar una opinión pública, mientras no se acredite conforme a la ley la responsabilidad penal de aquella (Corte IDH. 25 de noviembre de 2004, párr. 160).

Una derivación importante en el marco de procesos penales, que surge de la aplicación del principio en el ámbito interno de los Estados, es la 
referida a los límites necesarios a la aplicación de las medidas privativas de libertad para procesados, en concreto: la excepcionalidad y uso limitado que debe darse a la prisión preventiva.

El principio de presunción de inocencia, para la Corte, subyace el propósito de las garantías judiciales, al afirmar que una persona es inocente hasta que su culpabilidad sea demostrada; del mismo, se deriva la obligación estatal de no restringir la libertad del detenido más allá de los límites estrictamente necesarios para asegurar que no impedirá el desarrollo eficiente de las investigaciones y que no eludirá la acción de la justicia, pues la prisión preventiva es una medida cautelar, no punitiva (Corte IDH. 12 de noviembre de 1997, párr. 77).

Por ello, se incurriría en una violación a la Convención al privar de libertad, por un plazo desproporcionado, a personas cuya responsabilidad criminal no ha sido establecida, puesto que equivaldría a anticipar la pena, lo cual contraviene los principios generales del derecho universalmente reconocido (Corte IDH. 21 de noviembre de 2007, párr. 146; 7 de septiembre de 2004, párr. 180 y 30 de octubre de 2008, párr. 110).

Este concepto está expresado en múltiples instrumentos del derecho internacional de los derechos humanos y, entre otros, en el Pacto Internacional de Derechos Civiles y Políticos, que dispone que la prisión preventiva de las personas que hayan de ser juzgadas no debe ser la regla general (art. 9.3). En caso contrario, se estaría cometiendo una injusticia al privar de libertad, por un plazo desproporcionado respecto de la pena que correspondería al delito imputado, a personas cuya responsabilidad criminal no ha sido establecida (Corte IDH. 12 de noviembre de 1997, párr. 77).

La Corte ha entendido en el fallo Caso Palamara Iribarne Vs. Chile (Corte IDH.22 de noviembre de 2005, párr. 206)que,teniendo en cuenta la presunción de inocencia, los requisitos para que se pueda emitir un auto de procesamiento son diferentes a los exigidos para ordenar prisión preventiva, dado que esta última exige, además de un grado razonable de imputabilidad de la conducta delictiva al procesado, que la privación de la libertad sea necesaria para evitar un daño al proceso que pueda ser ocasionado por el acusado.

Y ello es así en función de que el Tribunal entiende que la prisión preventiva es la medida más severa que se puede aplicar al imputado de un delito, motivo por el cual su aplicación debe tener un carácter excepcional, en virtud de que se encuentra limitada por los principios de legalidad, presunción de inocencia, necesidad y proporcionalidad, indispensables en una sociedad democrática (Corte IDH. 25 de noviembre de 2005, párr. 106). Dicha afirmación se condice con lo sostenido por el Principio trigésimo sexto del conjunto de principios para la protección de todas las personas sometidas a cualquier forma de detención o prisión de las Naciones Unidas que establece que: 1 . [s] e presumirá la inocencia de toda persona sospechosa o acusada de un delito y se la tratará como tal mientras no haya sido probada su culpabilidad conforme al derecho en un juicio público en el que haya gozado de todas las garantías necesarias para su defensa (Corte IDH. 25 de noviembre de 2005, párr. 159), y que ha sido valorado por el máximo Tribunal en materia de Derechos Humanos para definir el correcto alcance de la garantía en estudio.

\section{DERECHO AL PROCESO EN PLAZO RAZONABLE}

El numeral 1 del artículo 8 de la Convención Americana sobre Derechos Humanos establece que toda persona tiene derecho a ser oída con las debidas garantías, dentro de un plazo razonable, por un juez o tribunal competente, independiente e imparcial establecido con anterioridad por la ley, en la sustanciación de cualquier acusación penal formulada contra ella ${ }^{1}$.

1 Esta garantía ya estaba consagrada en el sistema interamericano en la Declaración Americana de Derechos 
La Corte Interamericana sostiene que el principio de plazo razonable que consagra dicha norma, derecho al que también alude el artículo 7.5 de la Convención, aunque referido específicamente a la prisión preventiva, tiene como finalidad impedir que los acusados de un delito permanezcan largo tiempo bajo acusación y asegurar que ésta se decida prontamente (Corte IDH. 12 de noviembre de 1997, párr. 70).

El Tribunal ha entendido que una persona sobre la cual recae una imputación de haber cometido un delito tiene el derecho, en los términos del artículo 8.1, en caso de ser penalmente perseguida, a ser puesta sin demora a disposición del órgano de justicia o de investigación competente, tanto para posibilitar la sustanciación de los cargos que pesan en su contra, en su caso, como para la consecución de los fines de la administración de justicia, en particular la averiguación de la verdad.

La razón de esto fundamentó la Corte en el caso Yvon Neptune vs. Haití, es que la persona se encuentra sujeta a imputación y en un estado de incertidumbre que hace necesario que su situación jurídica sea sustanciada y resuelta lo más pronto posible, a fin de no prolongar indefinidamente los efectos de una persecución penal, teniendo en cuenta además que en el marco del proceso penal su libertad personal puede ser restringida. A su vez, confluye con lo anterior la necesidad de posibilitar y hacer efectiva la determinación de los hechos que se investigan y, en su caso, de las correspondientes responsabilidades penales, en atención a la necesidad de proteger y garantizar los derechos de otras personas perjudicadas (Corte IDH. 6 de mayo de 2008, párr. 81).

En cuanto su alcance, el tribunal interamericano ha indicado en casos como Bayarri vs. Argentina y 19 Comerciantes us. Colombia, que el plazo

y Deberes del Hombre, cuyo artículo XXV dispone que todo individuo privado de libertad tiene derecho "a ser juzgado sin dilación injustificada". También se encuentra prescripta en el Pacto Internacional de Derechos Civiles y Políticos como el "derecho a ser juzgado sin dilaciones indebidas" (artículo 14.3.c). razonable debe comprender todo el procedimiento, incluyendo los recursos de instancia que pudieran eventualmente presentarse, apuntando que el proceso termina cuando se dicta sentencia definitiva y queda firme el asunto (Corte IDH. 30 de octubre de 2008, párr. 105).

La razonabilidad del plazo al que se refiere el precepto se debe apreciar, entonces, en relación con la duración total del proceso, y desde el primer acto procesal (Corte IDH. 7 de septiembre de 2004, párr. 168).En el caso Suárez Rosero us. Ecuador, el primer acto del procedimiento lo constituyó la aprehensión del señor Suárez Rosero y, por lo tanto, a partir de ese momento debía comenzar a apreciarse el plazo (Corte IDH.12 de noviembre de 1997, párr. 70). Más adelante, la Corte agregó que cuando no es aplicable esta medida de coerción pero ya se halla en marcha un proceso penal, dicho plazo debiera contarse a partir del momento en que la autoridad judicial toma conocimiento del caso (Corte IDH. 7 de septiembre de 2004, párr. 168).

En Bayarrivs. Argentina la Corte estableció que en materia penal el plazo comienza cuando se presenta el primer acto de procedimiento dirigido en contra de determinada persona como probable responsable de cierto delito (Corte IDH. 30 de octubre de 2008, párr. 105; 6 de abril de 2006, párr. 150 y 4 de julio de 2006, párr. 195).

Al momento de delimitar su contenido, la Corte IDH admitió que el plazo razonable no es un concepto de sencilla definición. Para precisarlo echó mano a los elementos que había señalado la Corte Europea de Derechos Humanos en distintos fallos en los cuales se había analizado este principio, pues el artículo 8.1 de la Convención Americana es equivalente, en lo esencial, al artículo 6 del Convenio Europeo para la Protección de Derechos Humanos y de las Libertades Fundamentales.

Así, de acuerdo con la doctrina de la Corte Europea sentada en casos como Motta (judgment of 19 February 1991, Series A no. 195-A, p. 30) o Ruiz Mateos v. Spain (judgment of 23 June 1993, 
Series A no. 262, p. 30), en el precedente Genie Lacayo vs. Nicaragua (29 de enero de 1997, párr.77) se dejó sentado también para nuestro sistema interamericano, que para determinar la razonabilidad del plazo en el cual se desarrolla el proceso, se deben tomar en cuenta tres elementos:

a) la complejidad del asunto, referida tanto a cuestiones de hecho como de derecho presentes en el caso;

b) la actividad procesal del interesado, que pudiera provocar una demora indebida en la tramitación del proceso; y

c) la conducta de las autoridades judiciales, vinculada a dilaciones indebidas que pudieran provenir de la falta de diligencia y cuidado que deben tener los tribunales de justicia (Corte IDH. 6 de mayo de 2008, párr. 83) o en general los sujetos procesales que intervienen en el procedimiento con facultad para diligenciar actuaciones como en algunas legislaciones el Ministerio Público Fiscal o la policía (Corte IDH. 27 de noviembre de 2008, párr. 2).

Estos tres elementos fueron también mencionados en casos como 19 Comerciantes us. Colombia (párrafo 190); Hilaire, Constantine, Benjamín y otros us. Trinidad y Tobago (párrafo 43), Tibi vs. Ecuador (párrafo 175); Hermanas Serrano Cruz vs. El Salvador (párrafo 67); Acosta Calderón vs. Ecuador (párrafo 105); García Asto y Ramírez Rojas vs. Perú (párrafo 166); Masacre de Pueblo Bello vs. Colombia (párrafo 171); Ximenes Lopes vs. Brasil (párrafo 196); López Álvarez Vs. Honduras (párrafo 132); Baldeón García vs. Perú (párrafo 151); Vargas Areco vs. Paraguay (párrafo 102); Escué Zapata vs. Colombia (párrafo 102); La Cantuta vs. Perú (párrafo 196), Salvador Chiribogavs. Ecuador (párrafo 78); Apitz Barbera y otros ("Corte Primera de lo Contencioso Administrativo") vs. Venezuela (párrafo 172), y Heliodoro Portugal vs. Panamá (párrafo149), entre otros.

Como puede verse, esta doctrina legal fue sostenida en el tiempo a través de numerosos precedentes, hasta que en el caso Valle Jaramillo y Otros vs. Colombia (Corte IDH. 27 de noviembre de 2008, párr. 155), la Corte estableció un cuarto elemento. En concreto, precisó que en el análisis de la razonabilidad del plazo se debe tomar en cuenta la afectación generada por la duración del procedimiento en la situación jurídica de la persona involucrada en el mismo, considerando, entre otras circunstancias, la materia objeto de controversia. Se sostuvo que "si el paso del tiempo incide de manera relevante en la situación jurídica del individuo, resultará necesario que el procedimiento corra con más diligencia a fin de que el caso se resuelva en un tiempo breve".

Esta línea fue ratificada en fallos posteriores, como en el caso Comunidad Indígena XákmokKásek vs Paraguay (24 de agosto de 2010, Serie C No. 214, párr. 133), donde se reiteró como esta cuarta pauta de análisis tal cual fue expresada en Valle Jaramillo. Y en el mismo sentido, también en el caso Gomes Lund y otros (Guerrilha do Araguaia) vs. Brasil (24 de noviembre de 2010, párr. 219).

En el marco de la garantía del plazo razonable de duración del proceso, la Corte ha dicho, también, que el derecho de acceso a la justicia no se agota en que se tramiten procesos internos, sino que debe además asegurar en tiempo razonable, el derecho de la víctima o sus familiares a saber la verdad de lo sucedido y a que se sancione a los eventuales responsables (Corte IDH. 5 de julio de 2004, párr. 188; 4 de julio de 2007, párr. 102; 18 de septiembre de 2003, párr. $114 ; 1^{\circ}$ de julio de 2006, párr. 289 y 6 de abril de 2006, párr. 166).

En casos que hemos citado, como 19 Comerciantes vs. Colombia, expuso también el tribunal interamericano que una demora prolongada puede llegar a constituir por sí misma, en ciertos casos, una violación de las garantías judiciales (CorteIDH. 5 de julio de 2004, párr.191). Y que corresponde al Estado hacer saber y probar la razón por la que se ha requerido más tiempo del que sería razonable, en principio, para dictar sentencia definitiva en un caso particular, de conformidad con los criterios indicados. Para la Corte, la falta de respuesta estatal es un elemento determinante al valorar si se ha dado un incumplimiento alcontenido de los artículos 8.1 y 25.1 de la Convención Americana, pues tiene 
relación directa con el principio de efectividad que debe irradiar el desarrollo de tales investigaciones. De tal forma el Estado, al recibir una denuncia penal, debe realizar una investigación seria e imparcial, pero también debe brindar en un plazo razonable una resolución que resuelva el fondo de las circunstancias que le fueron planteadas (Corte IDH. 20 de noviembre de 2007, párr. 115).

\section{DERECHO AL JUEZ NATURAL}

El juez natural deriva su existencia y competencia de la ley considerada en sentido formal, es decir, aquella que emana de los órganos legislativos constitucionalmente previstos y democráticamente elegidos, según el procedimiento que la Carta Magna de los estados prevea (Corte IDH. 9 de mayo de 1986 y 17 de noviembre de 2009, párr. 77), y este es, a su vez, un "principio básico del debido proceso" (Corte IDH. 25 de noviembre de 2004, párr. 143). Esta garantía del debido proceso debe analizarse de acuerdo al objeto y fin de la Convención Americana, cual es la eficaz protección de la persona humana (Corte IDH.11 de mayo de 2007, párr. 200). A su vez, la Corte prescribe que el estado no debe crear "tribunales que no apliquen normas procesales debidamente establecidas para sustituir la jurisdicción que corresponda normalmente a los tribunales ordinarios". Esto se vincula al debido proceso, dado que este último implica la intervención de un órgano judicial independiente e imparcial, apto para determinar la legalidad de las actuaciones que se cumplan, incluso tratándose de un estado de excepción (Corte IDH. 25 de noviembre de 2004, párr. 144).

Dentro de esta garantía, la Corte desarrolla lineamientos respecto a la jurisdicción militar. En términos generales entiende que "cuando la justicia militar asume competencia sobre un asunto que debe conocer la justicia ordinaria se ve afectado el derecho al juez natural y, a fortiori, el debido proceso, el cual, a su vez, encuéntrese íntimamente ligado al propio derecho de acceso a la justicia" (Corte IDH. 25 de noviembre de 2004, párr. 141; 26 de septiembre de 2006, párr.
131; 22 de noviembre de 2005, párr. 143; 5 de julio de 2004, párr. 167; 11 de mayo de 2007, párr. 200; 30 de mayo de 1999, párr. 128; 29 de noviembre de 2006, párr. 142 y 4 de julio de 2007, párr. 105).

A su vez, establece que "en un Estado democrático de Derecho la jurisdicción penal militar ha de tener un alcance restrictivo y excepcional y estar encaminada a la protección de intereses jurídicos especiales, vinculados con las funciones que la ley asigna a las fuerzas militares. Así, debe estar excluido del ámbito de la jurisdicción militar el juzgamiento de civiles y sólo debe juzgar a militares por la comisión de delitos o faltas que por su propia naturaleza atenten contra bienes jurídicos propios del orden militar" (Corte IDH. 25 de noviembre de 2004, párr. 142; 29 de noviembre de 2006, párr. 142; 26 de septiembre de 2006, párr. 131; 31 de enero de 2006, párr. 189; 23 de Noviembre de 2009, párr. 272 y 31 de agosto de 2010, párr. 160).

Además, la Corte explícitamente entiende que "la jurisdicción penal militar no es el fuero competente para investigar $y$, en su caso, juzgar y sancionar a los autores de violaciones de derechos humanos" (Corte IDH. 29 de noviembre de 2006, párr. 142 y 31 de enero de 2006, párr. 200). Así, en el caso Lori Berenson Mejía la Corte sostuvo que el procesamiento de civiles por el delito de traición a la patria en el fuero militar, "supone excluir al juez natural del conocimiento de estas causas" (Corte IDH. 25 de noviembre de 2004, párr. 141) y, por lo tanto, los tribunales militares que juzgaron a la presunta víctima (...) no cumplieron los requerimientos inherentes a las garantías de independencia e imparcialidad establecidas por el artículo 8.1 de la Convención Americana, como elementos esenciales del debido proceso legal" (Corte IDH. 25 de noviembre de 2004, párr. 146) y, más aun, considerando que en el caso en particular los jueces intervinientes actuaban "sin rostro", lo que impidió que el procesado conociera la identidad del juzgador y valorara su idoneidad, sumado a que la ley prohíbe la recusación de dichos jueces (25 de noviembre de 2004, párr. 147). 


\section{DERECHO A CONOCER PREVIA Y DETALLADAMENTE LA ACUSACIÓN}

El articulo 8.2.b de la Convención Americana consagra el derecho a conocer previa y detalladamente la acusación formulada. La Corte Interamericana de Derechos Humanos, siguiendo los postulados de la "Observación General No. 13 relativa a la Igualdad ante los tribunales y derecho de toda persona a ser oída públicamente por un tribunal competente establecido por la ley (art. 14)"del Comité de Derechos Humanos de las Naciones Unidas, entiende que el derecho a ser informado sin demora de la acusación exige que se la comunique al imputado, tan pronto como una autoridad la formule, surgiendo el derecho mencionado cuando en el curso de una investigación, un tribunal o una autoridad del Ministerio Público decida adoptar medidas procesales contra una persona sospechada de haber cometido un delito o la designe públicamente como tal, es decir, en forma previa a someterlo a un proceso (Corte IDH. 24 de junio de 2005, párr. 117 y 118; 7 de Septiembre de 2004, párr. 187 y Corte Europea de Derechos Humanos. 25 de marzo de 1999, párr. 51). En el caso Palamare Iribarne vs. Chile el Tribunal estima "que se debe tomar en particular consideración la aplicación de esta garantía cuando se adoptan medidas que restringen (...) el derecho a la libertad personal" (Corte IDH. 22 de noviembre de 2005, párr. 225). Tal omisión, por ejemplo, torna inaplicable el derecho a recurrir el fallo sancionatorio.

Debe tenerse presente que para que este derecho opere en plenitud es necesario que la acusación se notifique antes de que el inculpado rinda su primera declaración (Corte IDH. 24 de junio de 2005, párr. 118; 22 de noviembre de 2005, párr. 225 y 1 de febrero de 2006, párr. 149). De esta manera, cumple su fin primordial: posibilitar preparar(¿cuál de los dos verbos? debidamente su defensa (Corte IDH. 24 de junio de 2005, párr. 118 y 1 de febrero de 2006, párr. 149), ya que constituye la referencia indispensable para el ejercicio de la defensa del imputado y la consecuente consideración del juzgador en la sentencia (Corte IDH. 20 de junio de 2005, párr. 67).
En cuanto a las exigencias formales de la acusación, la Corte no impone forma alguna, incluso reconoce que pueda hacerse verbalmente, pero siempre que se indique la normativa aplicable, los supuestos de hechos y las razones en que se basa (Corte IDH. 24 de junio de 2005, párr. 118; 7 de Septiembre de 2004, párr. 187 y Corte Europea de Derechos Humanos. 25 de marzo de 1999, párr. 51). En algunos de sus pronunciamientos, el Tribunal Interamericano hizo énfasis en que esa descripción de los hechos debe ser clara, detallada y precisa (Corte IDH. 20 de junio de 2005, párr. 67).

De todas formas, la Corte reconoce que la calificación jurídica de los hechos pueda ser modificada durante el proceso por el órgano acusador o por el juzgador, lo que no implica una violación del derecho de defensa "cuando se mantengan sin variación los hechos mismos y se observen las garantías procesales previstas en la ley para llevar a cabo la nueva calificación. (Corte IDH. 20 de junio de 2005, párr. 67)”.

También puede suceder que al evacuar pruebas durante el juicio oral, se acredite la existencia de nuevos hechos o circunstancias no previstos en la acusación. En tal hipótesis, la Corte entiende que el Ministerio Público puede formular la "Acusación alternativa" o la "Ampliación de la acusación", a fin de promover la modificación del objeto del proceso (Corte IDH. 20 de junio de 2005, párr. 71).

En el caso Fermín Ramírez vs. Guatemala, el Tribunal consideró que emana del art. 8.2 inc.b y c de la Convención Americana el "principio de coherencia o de correlación entre acusación y sentencia", el cual constituye una garantía fundamental en el debido proceso penal. Este principio implica que la sentencia debe versar únicamente sobre hechos o circunstancias contemplados en la acusación. La Corte, citando a su par europea en el caso Pélissier y Sassi us. Francia, entendió que se vulneró esta garantía cuando los peticionarios conocieron la recalificación de los hechos solo a través de la sentencia del Tribunal de Apelaciones de su país, alterando sustancialmente la sentencia los términos de la acusación inicial (Corte IDH. 20 de junio de 2005, párr. 67, 68 y 69). 


\section{DERECHO DE TIEMPO Y FORMA PARA LA PREPARACIÓN DE LA DEFENSA}

La Corte afirma que el derecho de defensa puede ejercerse desde que se señala a una persona como posible autor o partícipe de un hecho punible, y culmina cuando finaliza el proceso (Corte IDH. 17 de noviembre de 2009, párr. 29; 12 de noviembre de 1997, párr. 71; 12 de agosto de 2008, párr. 148 y 30 de octubre de 2008, párr. 105), incluyendo, en su caso, la etapa de ejecución de la pena. Impedir que la persona ejerza su derecho de defensa implica potenciar los poderes investigativos del Estado en desmedro de los derechos fundamentales de la persona investigada. Esta fundamental garantía obliga al Estado a tratar al individuo en todo momento como un verdadero sujeto del proceso, en el más amplio sentido de este concepto (CorteIDH. 17 de noviembre de 2009, párr. 29 y 26 de noviembre de 2010, párr. 154).

Justamente, uno de los aspectos del derecho de defensa es contar con el tiempo y los medios adecuados para prepararla adecuadamente, consagrada en el art. 8.2.c. de la Convención Americana.

En varias oportunidades, la Corte manifestó que la presencia y actuación de los defensores no deben ser meramente formales (Corte IDH. 30 de mayo de 1999, párr. 141 y 25 de noviembre de 2004, párr. 67), fijando en distintos casos estándares para que esto no suceda. Por ejemplo, en el caso Castillo Petruzzi us. Perú, el Tribunal Interamericano tomó los parámetros fijados por el numeral 8 de los Principios Básicos sobre la función de los Abogados relativo a las salvaguardias especiales en asuntos penales ${ }^{2}$, y declaró que a "toda persona arrestada, detenida o presa, se le facilitará oportunidades, tiempo e instalaciones

2 Principios Básicos sobre la Función de los Abogados relativo a las salvaguardias especiales en asuntos penales, aprobados por el Octavo Congreso de las Naciones Unidas sobre Prevención del Delito y Tratamiento del Delincuente, celebrado en La Habana (Cuba) de 27 de agosto al 7 de septiembre de 1990. adecuadas para recibir visitas de un abogado, entrevistarse con él y consultarle, sin demora, interferencia ni censura y en forma plenamente confidencial (Corte IDH. 30 de mayo de 1999, párr. 141 y 25 de noviembre de 2004, párr. 67)".

Esta garantía abarca también el acceso del inculpado al conocimiento del expediente llevado en su contra (Corte IDH. 22 de noviembre de 2005, párr. 170; 17 de noviembre de 2009, párr. 54 y 26 de noviembre de 2010, párr. 156.). En el caso Castillo Petruzi y otros us. Perú, la Corte entendió violado el derecho de defensa como consecuencia de que los abogados sólo tuvieron acceso al expediente el día anterior a la emisión de la sentencia de primera instancia (Corte IDH. 30 de mayo de 1999, párr. 141 y 25 de noviembre de 2004, párr. 67).

En el caso Chaparro Álvarez y Lapo Íñiguez vs. Ecuador, el Tribunal si bien reconoció que no es necesario la inmediación de las partes en la producción de todo tipo de prueba, en el caso citado, la falta de ello implicó la violación de derecho de defensa, ya que era la única prueba técnica en contra de las victimas, la cual fue tenida en cuenta por el juzgador en sus decisiones, sin poder ser remplazada por otra medida probatoria (Corte IDH. 21 de noviembre de 2007, párr. 152).

Asimismo, el derecho a contar con los medios y tiempo para la preparación adecuada de la defensa implica la posibilidad de presentar pruebas de descargo (Corte IDH. 30 de mayo de 1999, párr. 141, 31 de enero de 2001, párr. 83 y 25 de noviembre de 2004, párr. 67); el conocimiento oportuno y completo de los cargos que se les hacían a los inculpados (Corte IDH. 30 de mayo de 1999, párr. 141; 31 de enero de 2001, párr. 83; 25 de noviembre de 2004, párr. 67 y 20 de junio de 2005, párr. 69); el libre acceso al acervo probatorio (Corte IDH. 31 de enero de 2001, párr. 83); la posibilidad de contrainterrogar a los testigos en cuyos testimonios se baso la acusación (Corte IDH. 31 de enero de 2001, párr. 83; 8 de marzo de 1998, párr. 152 y 30 de mayo de 1999, párr. 154). Tan ampliamente se lo considera a este derecho que implica la posibilidad de conocer a los juzgadores 
para poder, en su caso, si se dan las condiciones legales, recusarlos (Corte IDH. 25 de noviembre de 2004, párr. 67).

En relación al plazo, el Tribunal Interamericano, si bien no ha fijado un plazo, ha considerado que en un caso se violó esta garantía cuando se otorgó un plazo extremadamente corto, teniendo en cuenta dos parámetros: la necesidad de examen de la causa y la revisión del acervo probatorio a que tiene derecho cualquier imputado (Corte IDH. 31 de enero de 2001, Serie C No. 71, párr. 83).

Nos parece importante resaltar que la Corte reconoció la obligación de estado de respetar este derecho incluso en procesos en el fuero militar (Corte IDH. 25 de noviembre de 2004, párr. 67). Para finalizar, con el análisis del art. 8.2.c, "la Corte también ha señalado que el derecho individual de solicitar asistencia consular a su país de nacionalidad debe ser reconocido y considerado en el marco de las garantías mínimas para brindar a los extranjeros la oportunidad de preparar adecuadamente su defensa y contar con un juicio justo (21 de noviembre de 2007, párr. 164)". Este derecho, según jurisprudencia constante de la Corte, implica que el extranjero detenido al momento de ser privado de su libertad, y antes de que rinda su primera declaración ante la autoridad, debe ser notificado de su derecho a establecer contacto con un funcionario consulare informarle que se halla bajo custodia del Estado. El cónsul podría asistir al detenido en diversos actos de defensa, como el otorgamiento o contratación de patrocinio letrado, la obtención de pruebas en el país de origen, la verificación de las condiciones en que se ejerce la asistencia legal y la observación de la situación que guarda el procesado mientras se halla en prisión (Corte IDH. 21 de noviembre de 2007, párr. 164; 18 de Septiembre de 2003, párr. 130; 7 de Septiembre de 2004, párr. 112 y 195; 11 de mayo de 2007, párr. 116; 1 de octubre de 1999, párr. 86, 106 y 122).

\section{CONCLUSIONES}

La Corte Interamericana de Derechos Humanos es un Tribunal que desde su creación se ha caracterizado por el desarrollo progresivo del Derecho Internacional de los Derechos Humanos en su jurisprudencia. Este desarrollo se manifiesta, con mucha intensidad en el tratamiento del debido proceso, las garantías judiciales y encuentra su máxima expresión en el "Derecho a la Verdad".

Actualmente, el concepto de debido proceso se ha extendido hacia ámbitos fuera del control jurisdiccional, alcanzando así esferas administrativas del Estado. Los elementos del debido proceso, adjetivo más desarrollado por la Corte, son el concepto de plazo razonable y la noción de tribunal competente, independiente e imparcial. En cuanto al plazo razonable, la Corte ha tomado los criterios utilizados por la Corte Europea de Derechos Humanos, que han sido aplicados en la mayoría de los casos analizados por el Tribunal, a excepción de aquellos en los cuales las circunstancias especiales ameritaban, para su justo tratamiento, apartarsede estos criterios. La violación del plazo razonable ha sido considerado, en numerosas oportunidades, como una violación per se del artículo 8 de la Convención.

En cuanto a la noción de independencia, imparcialidad y competencia del tribunal, el estudio de este elemento se ha centrado en la jurisprudencia del Tribunal Interamericano, en el análisis de las jurisdicciones militares. En esta materia, vemos un desarrollo bastante progresivo que admite cada vez menos este tipo de jurisdicción.

En cuanto a las garantías mínimas que deben respectarse en el marco de un proceso judicial (Art. 8.2 a, b, c, d, e, f, g y h), la Corte no ha realizado un desarrollo detallado de cada una de estas. Resaltamos, sin embargo, el análisis que hace la Corte de la garantía del imputado en conocer su acusación de manera acabada, a la luz de Declaración de Principios Básicos sobre la Función de los abogados relativo a las salvaguardias especiales en asuntos penales, aprobados por el Octavo Congreso de las Naciones Unidas sobre Prevención del Delito y Tratamiento del Delincuente, celebrado en La Habana (Cuba) de 27 de agosto al 7 de septiembre de 1990. Esa interpretación es, de alguna manera,demasiado extensiva ya que 
estaría utilizando fines hermenéuticos, un texto no vinculante que se encuentra fuera del sistema regional. Remarcamos, asimismo,la ampliación que ha efectuado la Corte del tradicional principio non bis in idem, ya que el Tribunal considera que el mismo no trata la identidad de hechos sino de causa.

En cuanto a la protección judicial consagrada en el artículo 25, la misma ha sido tratada casi de manera constante por la Corte Interamericana con relación a la violación del artículo 1.1, sosteniendo el Tribunal que, en virtud de estas disposiciones, los recursos que pone el Estado en manos del individuo deben ser efectivos.

El Tribunal ha hecho un análisis de la violación del artículo 25 en conjunto con la violación del artículo 7. Uno de los temas en los que encontramos una labor creativa de la Corte es el referido a las leyes de amnistía o auto amnistía,consideradas por el Tribunal incompatibles con la Convención Americana e incluso habiendo llegado este a declararlas ineficaces al interior del sistema jurídico en cuestión.

En cuanto el Derecho a la Verdad, el mismo ha sido desarrollado por la labor individual de dos de los magistrados de la Corte, el Juez A. CancadoTrindade y el Juez H. Salgado Pesantes, y ha sido definido como conditio sine qua non para poder hacer efectivo el derecho a las garantías judiciales con una dimensión individual y otras colectiva. Se ha señalado, asimismo, la necesidad de desarrollar una doctrina que lo incorpore en las normas positivas. CancadoTrindade ha manifestado, incluso, que la violación al derecho a la verdad constituye una violación al Jus Cogens. Sin embargo, surge en el seno del mismo Tribunal una postura opuesta a esta que niega la autonomía de este "nuevo derecho". Creemos que el Tribunal en su conjunto se inclinara por esta postura, ya que parecería vislumbrarse en su reciente jurisprudencia.

\section{RETOS}

A pesar de la saludable tendencia integradora $y$ de progresividad ampliada que se observa en la jurisprudencia de la Corte relacionada con las garantías judiciales, queda aún como desafío el avance hacia un desarrollo jurisprudencial detallado sobre las garantías mínimas con que ha de contar un proceso, con el fin de diseñar la idea del debido proceso con un contenido que pueda servir de guía a los Estados parte para su réplica interna y adaptación convencional.

Es deseable que exista una definición sobre el derecho a la verdad como derecho autónomo que pareció emerger en los primeros votos de Cançado Trindade y ampliado luego en el pensamiento de diferentes jueces, aunque con oposiciones fundadas de otros. Por la implicancia que tiene para una visión unificada de los derechos previstos en los arts. 8 y 25 , constituye, sin duda, un paso a dar la afirmación de un verdadero criterio definitivo en relación a ello.

\section{REFERENCIAS}

Corte IDH. Caso Acosta Calderón Vs. Ecuador. Fondo, Reparaciones y Costas. Sentencia de 24 de junio de 2005. Serie C No. 129.

Corte IDH. Caso Almonacid Arellano y otros Vs. Chile. Excepciones Preliminares, Fondo, Reparaciones y Costas. Sentencia de 26 de septiembre de 2006. Serie C No. 15.

Corte IDH. Caso Apitz Barbera y otros ("Corte Primera de lo Contencioso Administrativo") Vs. Venezuela. Excepción Preliminar, Fondo, Reparaciones y Costas. Sentencia de 5 de agosto de 2008. Serie C No. 182.

Corte IDH. Caso Baldeón García vs. Perú. Fondo, Reparaciones y Costas. Sentencia de 6 de abril de 2006. Serie C No. 147.

Corte IDH. CasoBarretoLeivaVs. Venezuela. Fondo, Reparaciones y Costas. Sentencia de 17 de noviembre de 2009. Serie C No. 206.

Corte IDH. Caso Bayarrivs. Argentina. Excepción Preliminar, Fondo, Reparaciones y Costas. Sentencia de 30 de octubre de 2008. Serie C No. 187. 
Corte IDH. Caso Blake Vs. Guatemala. Fondo. Sentencia de 24 de enero de 1998. Serie CNo. 3.

Corte IDH.Caso Bueno Alves vs. Argentina. Fondo, Reparaciones y Costas. Sentencia 11 de mayo de 2007. Serie C No 164.

Corte IDH. Caso Bulacio vs. Argentina. Fondo, Reparaciones y Costas. Sentencia de 18 de septiembre de 2003, Serie C No. 100.

Corte IDH. Caso Castillo Petruzzi y otros Vs. Perú. Fondo, Reparaciones y Costas. Sentencia de 30 de mayo de 1999. Serie C No. 52.

Corte IDH. Caso Cabrera García y Montiel Flores Vs. México. Excepción Preliminar, Fondo, Reparaciones y Costas. Sentencia de 26 de noviembre de 2010. Serie C No. 220.

Corte IDH. Caso Cantoral Benavides Vs. Perú. Fondo. Sentencia de 18 de agosto de 2000. Serie C No. 69.

Corte IDH. Caso Castillo Petruzzi y otros Vs. Perú. Fondo, Reparaciones y Costas. Sentencia de 30 de mayo de 1999. Serie C No. 52.

Corte IDH. Caso Chaparro Álvarez y Lapo Íñiguez vs. Ecuador. Excepciones Preliminares, Fondo, Reparaciones y Costas. Sentencia de 21 de noviembre de 2007. Serie C No. 170.

Corte IDH. Caso Comunidad Indígena Xákmok Kásek vs. Paraguay. Sentencia del 24 de agosto de 2010. Serie C No. 214.

Corte IDH.Caso de la "Panel Blanca" (Paniagua Morales y otros) vs. Guatemala. Fondo, Sentencia 8 de marzo de 1998, Serie C No 37.

Corte IDH. Caso de la Masacre de la Rochela Vs. Colombia. Fondo, Reparaciones y Costas. Sentencia de 11 de mayo de 2007. Serie C No. 163.

Corte IDH. Caso de la Masacre de Pueblo Bello Vs. Colombia. Fondo, Reparaciones y Costas.

Sentencia de 31 de enero de 2006. Serie C No. 140.
Corte IDH. Caso de las Hermanas Serrano Cruz Vs. El Salvador. Fondo, Reparaciones y Costas. Sentencia de 01 de marzo de 2005. Serie CNo. 120.

Corte IDH. Caso de las Masacres de Ituango vs. Colombia. Excepciones Preliminares, Fondo, Reparaciones y Costas. Sentencia de $1^{\circ}$ de julio de 2006. Serie C No. 148.

Corte IDH.Caso de los "Niños de la Calle" (Villagrán Morales y otros) Vs. Guatemala. Fondo. Sentencia de 19 de noviembre de 1999. Serie C No. 63.

Corte IDH. Caso de los 19 Comerciantes Vs. Colombia. Fondo, Reparaciones y Costas. Sentencia de 5 de julio de 2004. Serie C No. 109.

Corte IDH. Caso del Tribunal Constitucional Vs. Perú. Fondo, Reparaciones y Costas. Sentencia de 31 de enero de 2001. Serie C No. 71.

Corte IDH. Caso Del Penal Miguel Castro Castro Vs. Perú. Interpretación de la Sentencia de Fondo, Reparaciones y Costas. Sentencia de 2 de agosto de 2008. Serie C No. 181.

Corte IDH. Caso Durand y Ugarte. Fondo. Sentencia de 16 de agosto de 2000. Serie CNo. 68.

Corte IDH. Caso Escué Zapata vs. Colombia. Fondo, Reparaciones y Costas. Sentencia de 4 de julio de 2007. Serie C No. 165.

Corte IDH. Caso Fernández Ortega y otros. Vs. México. Excepción Preliminar, Fondo, Reparaciones y Costas. Sentencia de 30 de agosto de 2010. Serie C No. 215.

Corte IDH.Caso Fermín Ramírez Vs. Guatemala. Fondo, Reparaciones y Costas. Sentencia de 20 de junio de 2005. Serie C No. 126.

Corte IDH. Caso García Asto y Ramírez Rojas Vs. Perú. Excepción Preliminar, Fondo, Reparaciones y Costas. Sentencia de 25 de noviembre de 2005. Serie C No. 137.

Corte IDH. Caso García Prieto y Otro vs. El Salvador. Excepciones Preliminares, Fondo, Reparaciones y Costas.Sentencia de 20 de noviembre de 2007, Serie C No. 168. 
Corte IDH.Caso Genie Lacayo vs. Nicaragua. Fondo, Reparaciones y Costas. Sentencia de 29 de enero de 1997. Serie C No. 30.

Corte IDH. Caso Gomes Lund y otros (Guerrilha do Araguaia) vs. Brasil. Sentencia de 24 de noviembre de 2010. Serie C No. 219.

Corte IDH. Caso Herrera Ulloa Vs. Costa Rica. Excepciones Preliminares, Fondo, Reparaciones y Costas. Sentencia de 2 de julio de 2004. Serie C No. 107.

Corte IDH. Caso Heliodoro Portugal vs. Panamá. Excepciones Preliminares, Fondo, Reparaciones y Costas. Sentencia de 12 de agosto de 2008. Serie C No. 186.

Corte IDH. Caso La Cantuta Vs. Perú. Fondo, Reparaciones y Costas. Sentencia de 29 de noviembre de 2006. Serie C No. 162.

Corte IDH. Caso Las Palmeras Vs. Colombia. Fondo. Sentencia de 6 de diciembre de 2001. Serie C No. 90.

Corte IDH. Caso Lori Berenson Mejía vs. Perú. Fondo, Reparaciones y Costas. Sentencia de 25 de noviembre de 2004. Serie C No. 119.

Corte IDH. Caso López Álvarez Vs. Honduras. Fondo, Reparaciones y Costas. Sentencia de 1 de febrero de 2006. Serie C No. 141.

Corte IDH. Caso Palamara Iribarne Vs. Chile. Fondo, Reparaciones y Costas. Sentencia de 22 de noviembre de 2005. Serie C No. 135.

Corte IDH. Caso Radilla Pacheco Vs. México. Excepciones Preliminares, Fondo, Reparaciones y Costas.Sentencia de 23 de Noviembre de 2009. Serie C No. 209.

Corte IDH. Caso Ricardo Canese vs. Paraguay. Fondo, Reparaciones y Costas. Sentencia de 31 de agosto de 2004. Serie C No. 111.
Corte IDH. Caso Rosendo Cantú y otra Vs. México. Excepción Preliminar, Fondo, Reparaciones y Costas. Sentencia de 31 de agosto de 2010 Serie C No. 216.

Corte IDH.Caso Suárez Rosero Vs. Ecuador. Fondo. Sentencia de 12 de noviembre de 1997. Serie C No. 35.

Corte IDH. Caso Tibi vs. Ecuador. Excepciones Preliminares, Fondo, Reparaciones y Costas. Sentencia de 7 de septiembre de 2004. Serie C No. 114.

Corte IDH. Caso Valle Jaramillo vs. Colombia. Sentencia del 27 de noviembre de 2008. Serie C No. 192.

Corte IDH. Caso Vélez Loor Vs. Panamá. Excepciones Preliminares, Fondo, Reparaciones y Costas. Sentencia de 23 de noviembre de 2010. Serie C No. 218.

Corte IDH. Caso Ximenes Lopes vs. Brasil. Fondo, Reparaciones y Costas. Sentencia de 4 de julio de 2006. Serie C No. 149.

Corte IDH. Caso Yvon Neptunevs. Haití. Fondo, Reparaciones y Costas. Sentencia de 6 de mayo de 2008. Serie C No. 180.

Corte IDH. El Derecho a la Información sobre la Asistencia Consular en el Marco de las Garantías del Debido Proceso Legal. Opinión Consultiva OC-16/99 del 1 de octubre de 1999. Serie A No. 16.

Corte IDH. La Expresión "Leyes" en el Artículo 30 de la Convención Americana sobre Derechos Humanos. Opinión Consultiva OC-6/86 del 9 de mayo de 1986. Serie A No. 6.

Corte Europea de Derechos Humanos, Caso Pélissier and Sassi vs. France, sentencia del 25 de marzo de 1999. 